\title{
Institutionalizing One Health: From Assessment to Action
}

Catherine C. Machalaba, Robert H. Salerno, Casey Barton Behravesh, Solomon Benigno, Franck C. J. Berthe, Stella Chungong, Sambe Duale, Ricardo Echalar, William B. Karesh, Henk Jan Ormel, Katharine Pelican, Mahmudur Rahman, Mark Rasmuson, Susan Scribner, John Stratton, Ludy Suryantoro, and Chadia Wannous

A One Health approach is critical to strengthening health security at country, regional, and global levels. However, operationally its uptake remains limited. Recent momentum in assessing capacity to effectively prevent, detect, and respond to disease threats has resulted in identification of gaps that require dedicated action. This article highlights relevant tools, standards, and guidance to assist countries and institutions in meeting the collective vision articulated at the 2018 Prince Mahidol Award Conference on "Making the World Safe from the Threats of Emerging Infectious Diseases." Taking stock of assessment findings, resources, priorities, and implementation initiatives across human and animal health, environment and disaster risk reduction sectors can help expand participation in global health security, target risk drivers, and form synergies for collective action and shared gains for both emerging and endemic disease challenges. In addition to health security gains, a multisectoral, One Health approach can drive benefits for wider health sector and global development goals.

Keywords: One Health, Zoonosis, Global health security, Environmental detection, International coordination

Catherine C. Machalaba, MPH, is a Policy Advisor, Health and Policy, and William B. Karesh, DVM, is Executive Vice President, Health and Policy, both at EcoHealth Alliance, New York, NY. Robert H. Salerno, MSc, is Technical Integration Manager; Solomon Benigno, DVM, is Southeast Asia Regional Director; Sambe Duale, MD, MPH, is Global Senior One Health Technical Advisor; Mark Rasmuson, MA, MPH, is Southeast Asia Regional Manager; and Susan Scribner, MPP, is Project Director; all in the USAID Preparedness \& Response Project, DAI Global Health, Bethesda, Maryland. Casey Barton Behravesh, MS, DVM, DrPH, DACVPM, is a Captain, US Public Health Service, and Director, One Health Office, National Center for Emerging and Zoonotic Infectious Diseases, Centers for Disease Control and Prevention, Atlanta, Georgia. Franck C. J. Berthe, DVM, PhD, is Senior Livestock Specialist, Agriculture Global Practice, World Bank, Washington, DC. Stella Chungong, MD, MPH, is Chief, Core Capacity Assessment, Monitoring and Evaluation Unit, and Ludy Suryantoro is Team Leader, Strategic Partnership for IHR and Health Security, Country Health Emergency Preparedness and International Health Regulations (2005); both at the World Health Organization, Geneva, Switzerland. Ricardo Echalar, MPH, is Senior Public Health Advisor, Office of Infectious Diseases, Emerging Threats Division, Bureau for Global Health, US Agency for International Development, Washington, DC. Henk Jan Ormel, DVM, is Senior Veterinary Policy Advisor, Animal Health Service, Food and Agriculture Organization of the United Nations, Rome, Italy. Katharine Pelican, DVM, PhD, is Associate Professor; Head, One Health Division; and Deputy Director and Principal Investigator, USAID One Health Workforce Project, Department of Veterinary Population Medicine, College of Veterinary Medicine, St. Paul, Minnesota. Mahmudur Rahman, MBBS, MPHM, PhD, is a consultant, Programme for Emerging Infections, IDD, icddr,b, Dhaka, Bangladesh. John Stratton, PhD, is Deputy Head, Regional Activities Department, World Organisation for Animal Health (OIE), Paris, France. Chadia Wannous, PhD, is Coordinator, Towards a Safer World Network for Pandemic Preparedness, Geneva, Switzerland. 
$\mathrm{O}$ Ne Health is NOW a well-recognized concept in global health security efforts in terms of its potential to contribute to the prevention of infectious diseases (both emerging and endemic), early detection and warning, response, and recovery. A multisectoral One Health approach demands an integrated and collaborative process to efficiently and effectively bring together information, capacity, and expertise within and across sectors to protect human and animal lives and our environment. On this basis, the tripartite collaboration among the Food and Agriculture Organization (FAO), the World Organisation for Animal Health (OIE), and the World Health Organization (WHO), through a memorandum of understanding, ${ }^{1}$ recently reaffirmed its commitment to multisectoral cooperation on disease risks at the human-animal-environment interface, and numerous other global and local actors have endorsed a One Health approach. ${ }^{2}$

In their efforts to meet obligations under the International Health Regulations (IHR) (2005), a critical mass of countries has now undergone capacity assessments (both voluntary self-assessment and Joint External Evaluations), and these countries are launching multisectoral national action plans for health security, antimicrobial resistance, climate resilience and health, and other areas of risk reduction for shared health threats. The relevance and importance of a One Health approach for the effective prevention, detection, and response to human and animal public health threats was emphasized throughout the Prince Mahidol Award Conference, held in Bangkok in February 2018. The conference was notable in bringing together experts from the human health, animal health (domestic and wildlife), and environment sectors, as well as in including infectious diseases and antimicrobial resistance together under its theme "Making the World Safe from the Threats of Emerging Infectious Diseases," reinforcing the importance of overall preparedness capacity in public health systems to advance health security.

While One Health achievements have been made within countries and are often supported by strong government buy-in, successes are sometimes uneven and, in many cases, can benefit from greater awareness, active collaboration, and integration across disciplines and sectors, which can result in strengthened systems, policies, and practices across the human-animal-environment interface. Multiple initiatives and tools are currently being deployed to assess, prioritize, and document One Health needs, gaps, and lessons learned through implementation and practice, supporting the vast knowledge network. These highlight the need for greater dissemination and linking of practical multisectoral field-based tools; in particular, there is an urgent need to reduce the assessment burden on countries, harmonize existing external assessments to avoid duplication, reinforce investment priorities, and, most crucially, support follow-up action on the findings based on a country's context. These should be pursued in ways that are inclusive of the environment sector, in addition to human and animal health, to expand opportunities to address emerging threats and optimize use of knowledge and resources, especially in the context of sustainable development. This article highlights opportunities to build on the current state of assessments to drive action that will help achieve the collective vision articulated at the 2018 Prince Mahidol Award Conference, including operationalizing One Health.

\section{Assessment of Core Capacity}

National and institutional capacity assessments are well recognized by countries and donors as being helpful in identifying gaps and aligning technical support and investments. For example, the OIE Performance of Veterinary Services (PVS) Pathway supports countries in strengthening animal health capacity. In the past decade, more than 140 countries have engaged in the pathway, with several countries undertaking re-assessment. ${ }^{3}$ The OIE PVS tool aligns critical competencies with the OIE's international standards for animals and animal products and listed priority diseases, which includes zoonoses, thereby promoting an important, if under-recognized, support for public health at country and global levels.

The IHR, a legally binding agreement among WHO member states, obligates countries to develop and maintain minimum core public health capacities, as stipulated in Article 54 of the regulations, to prevent, detect, and respond to human health events. ${ }^{4}$ Recent efforts to boost core capacities for IHR under initiatives such as the Global Health Security Agenda have largely been aligned to capacity benchmarking under the WHO's Joint External Evaluation (JEE) tool. Like the PVS tool for veterinary services, the JEE has provided a parallel assessment for public health, resulting in a publicly available report, and has catalyzed energy into coordination both at country and international levels for greater harmonization of the various assessment processes, interpretation of the results, and better alignment of resources for implementation.

While assessment protocols and tools may be relatively well established in specific sectors, bringing together tools and expertise from different sectors (see Table 1) in standard setting, assessment, and implementation can help better utilize findings of these assessments; identify possible information, infrastructure, and capacity synergies (eg, in surveillance, diagnostics, reporting, and workforce); and target unmet resource needs, thus enhancing animal, human, and environmental One Health collaboration at the national level. For example, the WHO-OIE operational framework delineates the wide-ranging benefits that can be derived from developing national strategies targeting joint capacity-building for the human and animal health sectors, such as sharing diagnostic test platforms or results and effective risk communication. ${ }^{11}$ IHR-PVS National Bridging Workshops are helping to identify opportunities 
for multisectoral collaboration at the systems level. During this process, animal health and public health officials from a country compare and map the results from their IHR JEE and PVS evaluation reports, which are similarly structured in evaluating health security and animal health systems, respectively, to identify gaps and plan for real-life operational collaboration between their sectors.

National Action Planning for Health Security (NAPHS) is another voluntary process, supported by $\mathrm{WHO}$ on request, with the aim of developing a costed national plan to improve the country's health security under the IHR. Multisectoral in nature, the process convenes relevant stakeholders and consolidates all assessment data and recommendations over several workshops to identify top priority activities to enhance IHR compliance. Through cost driver exercises, priority activities are costed and inputs for implementation identified. The process ends with a final list of objectives, targets, and a summary of planned activities and inputs, including unit costs.

In Tanzania, the planning process also identified the need for a high-level multisectoral coordination mechanism to map and ensure collaboration among multiple sectors. ${ }^{24}$ In 2018, the government of Tanzania, in part- nership with USAID and other development partners, launched the One Health Coordination Desk in the prime minister's office. The goal of this mechanism is to limit duplication in resource mapping and planning, ensure coordination with other existing disease response plans, and optimize synergies with the National Health Sector Development Plan. ${ }^{25}$

Several countries with multisectoral coordination mechanisms, often called "national One Health platforms," have led or participated in organizational capacity self-assessments that facilitate dialogue across One Health actors to identify entry points and design interventions that build human and institutional capacity to prevent, detect, and respond to public health events. In addition, both regional and national multisectoral coordination mechanisms for zoonotic diseases and antimicrobial resistance have used the One Health Systems Mapping and Analysis Resource Toolkit (OH-SMART ${ }^{\mathrm{TM}}$ ) to support multisectoral analysis and systems improvement to strengthen capacity, coordination, and collaboration for prevention, detection, and response to these infectious disease threats. Commitment to making the assessment tools and results of such processes public, and demonstrating clear value in doing so by systematically and consistently using findings,

Table 1. Examples of Resources from Different Sectors with One Health Relevance

\begin{tabular}{|c|c|}
\hline Type & Resource \\
\hline Regulatory and global normative frameworks & $\begin{aligned}> & \text { International Health Regulations (WHO) } \\
> & \text { Terrestrial and Aquatic Animal Health Codes (OIE) })^{5,6} \\
> & \text { Convention on Biological Diversity (CBD) }{ }^{7} \\
> & \text { Codex Alimentarius (FAO and WHO })^{8} \\
> & \text { Framework Convention on Climate Change (UNFCCC) } \\
> & \text { Sendai Framework for Disaster Risk Reduction (UNISDR) } \\
> & \text { WHO-OIE Operational Framework for Good Governance at the Human- } \\
& \text { Animal Interface: Bridging WHO and OIE Tools for the Assessment of } \\
& \text { National Capacities (WHO and OIE) }\end{aligned}$ \\
\hline Capacity assessments & $\begin{aligned}> & \text { Joint External Evaluation (JEE) for the IHR Monitoring and Evaluation } \\
& \text { Framework (WHO) } \\
> & \text { Performance of Veterinary Services (PVS) Evaluations, including PVS } \\
& \text { Evaluations for Aquatic Animal Health Services (OIE) } \\
> & \text { National capacity audits }\end{aligned}$ \\
\hline $\begin{array}{l}\text { Resource, prioritization, and action planning } \\
\text { processes and tools }\end{array}$ & $\begin{aligned} & \text { National Action Plans for Health Security (WHO) })^{15} \\
> & \text { One Health Zoonotic Disease Prioritization Tool and Workshop (CDC) })^{16,17} \\
> & \text { PVS Gap Analysis (OIE) } \\
> & \text { National Biodiversity Strategies and Action Plans (CBD) } \\
> & \text { National Adaptation Plans (UNFCCC) } \\
> & \text { National Action Plans for Disaster Risk Reduction (UNISDR and UNDP) } \\
> & \text { Health Security Financing Assessment Tool (World Bank) } \\
> & \text { Strategic Tool for Assessing Risk (STAR) and Vulnerability and Risk Analysis } \\
& \text { and Mapping (VRAM) (WHO) } \\
> & \text { Resource Mapping tool (WHO) }\end{aligned}$ \\
\hline $\begin{array}{l}\text { Multisectoral, One Health systems } \\
\text { improvement tools }\end{array}$ & $\begin{aligned}> & \text { IHR-PVS National Bridging Workshops (WHO and OIE) } \\
> & \text { One Health Systems Mapping and Analysis Resource Tool Kit (OH- } \\
& \left.\text { SMART }^{\mathrm{TM}}\right) \text { (University of Minnesota and US Department of Agriculture) }{ }^{22} \\
> & \text { One Health Assessment for Planning and Performance (OH-APP), } \\
& \text { Multisectoral Coordination Mechanism Self-Assessment Tool (USAID } \\
& \text { Preparedness \& Response project and DAI Global Health) }\end{aligned}$ \\
\hline
\end{tabular}


can help promote greater coordination and accountability across stakeholders.

\section{LESSONS LEARNED AND OpPORTUNITIES}

The 2018 Prince Mahidol Award Conference concluded with the presentation of the Bangkok Statement: A Call to Action on Making the World Safe from the Threats of Emerging Infectious Diseases, ${ }^{26}$ which synthesized challenges ahead and recommendations for a unified path forward. These recommendations are timely as countries undertake assessments and planning exercises and move to investment and implementation phases. Based on a panel discussion at the conference session on operationalizing One Health, this paper highlights lessons learned and further opportunities identified from many organizations and institutions, reinforcing a shared commitment to collaboration that in particular align with 4 key areas (discussed below) of the Bangkok Statement's Global Vision for Action. These areas emphasize compliance with the IHR, understanding and addressing drivers of disease, taking whole-of-society approaches for multisectoral preparedness strategies, and workforce development to tackle emerging threats.

This envisioned global action:

- Facilitates a full, universal, and sustained compliance with the IHR (2005) and aggressively adopts strategies and approaches that recognize that multisectoral responses are vital.

The IHR's monitoring and evaluation framework encourages a mix of self-evaluation, peer review, and voluntary external evaluations involving international and national experts. However, core capacities under IHR still remain unmet; as of 2015, only a third of WHO member states have reported capacity compliance. ${ }^{27} \mathrm{~A}$ suite of multisectoral tools has been developed to support countries in monitoring and evaluating progress in the implementation of the IHR, including the JEE and subsequent NAPHS. Simulation exercises and after-action reviews are also promoted for use to develop and refine capacity. In addition to a focus on international health security for the global good of protecting against novel emerging infectious diseases, investments must also have immediate value for countries in fighting existing, endemic disease burden and building sustainable and resilient human and animal health systems. This focus can also align with broader health sector goals, such as tackling antimicrobial resistance (AMR), pandemic influenza preparedness, and universal health coverage.

Multisectoral One Health approaches are vital to achieving improved capacity for disease prevention, detection, response, and recovery, given the high economic risks of disease epidemics and their wider societal and economic disruption (eg, projected losses from a severe pandemic total upwards of US $\$ 500$ billion per year). ${ }^{28}$ Earlier detection of disease threats at their source can mitigate their possible conse- quences and ultimately lead to fewer outbreak events, and effective response can help rapidly control disease spread and prevent epidemics. In addition to preparing for emerging infectious disease threats, capacity achievements that strengthen overall health systems and build an effective One Health workforce can also help countries address the burden of existing zoonotic and other infectious diseases, with potential benefits distributed among public health, animal production systems, environmental conservation, trade and travel, and other sectors.

- Invests in building an evidence base to improve our understanding of the drivers of disease emergence, including climate change, environmental degradation, and urbanization, and for tracking progress toward control of these threats.

Many of the upstream drivers of disease occur outside of the health sector (eg, extractive industries, livestock production, urbanization, conflict) and are multifactorial. Understanding and addressing them requires greater attention to prevention and detection of threats, ideally before they cause disease events. ${ }^{29,30}$ Effectively addressing these drivers brings in a wider range of potential partners, including the private sector, in a whole of government, whole of society approach to combine resources and solutions for global and local public health. ${ }^{31}$ Mainstreaming of disease prevention into national plans for climate adaptation, biodiversity, and other sectors can help reduce risks upstream and promote early warning for disease threats.

While in concept One Health includes the environment sector as one of its 3 primary pillars, in practice the integration of environmental dimensions in health security efforts has been limited to date. Despite the majority of recently emerging infectious diseases originating in wildlife and the increasing drivers changing ecological dynamics and facilitating increased wildlife-human or wildlife-domestic animal contact, ${ }^{32}$ wildlife and environmental health services remain neglected or isolated. ${ }^{33}$ However, they should be systematically assessed and integrated for relevance when considering investments in public health systems. A tool is currently being developed and piloted by the World Bank and EcoHeal th Alliance with initial input from partners including the UN Secretariat of the Convention on Biological Diversity to assess country capacity to manage and reduce environmental health threats to complement and reinforce efforts in the agriculture, human and animal health, and disaster risk reduction sectors. ${ }^{34}$

Some institutions are well placed to assist countries in addressing drivers of disease and potential impacts. For example, the FAO is working with countries on issues spanning livestock production, food safety, and food security. Similarly, the World Bank has released a series of resources on climate change and health, including geographic hotspots and a country diagnostic for vulnerability assessment. ${ }^{35,36}$ These and other risk profiling findings can inform where a One Health approach is highly relevant to address both current and anticipated infectious disease 
threats (among other shared health threats) from climate and other environmental change. Action at the intersections of human-animal-environmental health can also support broader global and cross-cutting frameworks, such as the UN Sustainable Development Goals. ${ }^{37,38}$

- Invests in and promotes "whole of society" approaches to ensure preparedness strategies and capabilities are in place to detect, respond to, and mitigate the effects of emergent health threats across the entirety of society by establishing and strengthening relationships between health and nonhealth sectors.

Rather than a one-size-fits-all approach, appropriate entry points for One Health approaches are context- and objective-specific. Integrated Disease Surveillance and Response (IDSR) reporting mechanisms and exercises, such as those supported by the US Centers for Disease Control and Prevention (CDC) One Health Zoonotic Disease Prioritization tool, WHO Strategic Risk Assessment (STAR), and WHO Vulnerability Risk Analysis and Mapping (VRAM) tools and workshops are helping to define country priorities with input from all relevant sectors. ${ }^{16}$ Initial exercises have identified common priorities across multiple countries and regions, providing an opportunity for information sharing and upscaling of lessons and successes.

There are extremely encouraging examples of countries mobilizing to embed One Health in multisectoral activities. For example, Bangladesh has established a One Health secretariat with dedicated government financing and key participation from 4 ministries identified. Through assessments and disease prioritization exercises, Bangladesh has costed capacity needs and shared priorities and has developed a range of joint surveillance activities, interdisciplinary networking forums to generate and disseminate information and knowledge, and institutional and international partnerships. These country-specific activities showcase the breadth of applications of One Health, as well as the importance of context-specific, locally driven, and value-added applications of One Health leadership, buy-in, and sustainability.

Given the high socioeconomic cost of pandemics and epidemics, there may be high return on investment from strengthening sectors and their coordination to mitigate disease risk. ${ }^{33,39}$ Economic analysis of costs and benefitsand their distribution to different sectors - of disease events and potential prevention and control strategies can inform individual sector decisions as well as finance ministry and parliamentary bodies that oversee budgets. ${ }^{40}$

The private sector and civil society also have important incentives and roles in strengthening health security to avoid workforce and other societal disruptions at local and international levels. Their meaningful engagement in health security can be better cultivated and harnessed; for example, employers can disseminate information to employees and contribute to disease reporting networks and risk reduction actions (eg, vaccination, biosecurity, etc). In the donor context, a One Health approach will ideally be built into project design and implementation to identify where multisectoral engagement is most relevant and provides greatest value. Strategic financing for health security should factor in the role and resources of different actors and align investments to reduce duplication and ensure gaps are being addressed. Importantly, enthusiasm for assessments must be paired with stakeholder commitments for follow-up action and financing to ensure assessments are purposeful for countries and promote progress benchmarking over time.

\section{- Builds a workforce in all relevant fields, including in health, agriculture, food production, and environment sectors, that demonstrates the core competencies necessary to meet the future challenges posed by these emerging threats.}

Core knowledge and technical skill gaps persist that must be urgently addressed, such as the limited basic veterinary and para-veterinary capacity in many countries. Human and animal health and environment sectors must be strengthened to function effectively to meet current demands; at the same time, coordination, collaboration, and communication mechanisms must be in place to support professionals and departments in working together across the spectrum of prevention, detection, response, and recovery for prepared and resilient human, animal, and environmental health systems. Field epidemiology training programs can promote coordination on joint human health and animal health, including domestic animals and wildlife. USAID investments in building One Health university networks and establishing multisectoral coordination mechanisms in Africa and Asia have been institutionalizing best practices in multisectoral One Health training, multisectoral planning, joint surveillance, and response.

\section{Conclusion}

The high interest and activity from organizations on One Health and health security-and increasing coordination between them-calls for a paradigm shift in how organizations approach the global challenge of zoonotic and emerging infectious diseases. Collaboration, coordination, and communication between institutions can set global examples for countries; at the same time, technical and donor institutions with field operations are actively sharing and adapting implementation based on country learning, collectively building the evidence base, and strengthening knowledge networks for One Health approaches.

Taking stock of the past 15 years of One Health momentum, the World Bank One Health Operational Framework provides an initial landscape and inventory of assessment, planning, and implementation resources from the human, animal, environmental, and disaster risk reduction sectors. ${ }^{34}$ Targeted to assist both client countries and donors in project design, it is intended to be informed 
and refined by new tools and approaches that respond to country needs and priorities. Ultimately, targeting appropriate entry points requires robust and risk-informed analysis to determine which sectors are relevant for risk management and risk reduction efforts. Successes in health security will be won by practical, sustained efforts at country and local contexts; appropriate support from regional and international partners that reduces burden and maximizes action can help advance country progress.

\section{ACKNOWLEDGMENTS}

This work was funded in part by the United States Agency for International Development (USAID) Emerging Pandemic Threats-2 program. We thank Anocha (Jane) Chuenwanta, Sara Lehman, and Khomkrit (Jean) Phakdeemai for their valuable collaboration.

\section{REFERENCES}

1. Memorandum of Understanding Between the United $\mathrm{Na}$ tions Food and Agriculture Organization and the World Organisation for Animal Health and World Health Organization Regarding Cooperation to Combat Health Risks at the Human-Animal-Ecosystems Interface in the Context of the "One Health" Approach and Including Antimicrobial Resistance. May 30, 2018. http://www.who.int/zoonoses/ MoU-Tripartite-May-2018.pdf?ua=1. Accessed August 23, 2018.

2. Food and Agriculture Organization of the United Nations, World Organisation for Animal Health, World Health Organization. The Tripartite's Commitment: providing multi-sectoral, collaborative leadership in addressing health challenges. October 2017. http://www.who.int/zoonoses/tripartite_oct2017.pdf. Accessed August 23, 2018.

3. World Organisation for Animal Health. PVS Pathway, 10 years together to improve veterinary services [press release]. May 23, 2017. http://www.oie.int/for-the-media/press-releases/ detail/article/pvs-pathway-10-years-together-to-improveveterinary-services/. Accessed August 23, 2018.

4. World Health Organization. International Health Regulations (2005). Geneva: World Health Organization. http://www .who.int/topics/international_health_regulations/en/. Accessed August 23, 2018.

5. World Organisation for Animal Health. Terrestrial Animal Health Code. 2018. http://www.oie.int/en/standard-setting/ terrestrial-code/. Accessed August 23, 2018.

6. World Organisation for Animal Health. Aquatic Animal Health Code. 2018. http://www.oie.int/standard-setting/ aquatic-code/access-online/. Accessed August 23, 2018.

7. United Nations Convention on Biological Diversity. 1992. https://www.cbd.int/doc/legal/cbd-en.pdf. Accessed August 23, 2018.

8. Food and Agriculture Organization of the United Nations. World Health Organization. Codex Alimentarius. Standards. 2018. http://www.fao.org/fao-who-codexalimentarius/codextexts/list-standards/pt/. Accessed August 23, 2018.
9. United Nations Framework Convention on Climate Change. Documents and Decisions. 2018. https://unfccc. int/documents. Accessed August 23, 2018.

10. United Nations Office for Disaster Risk Reduction. Sendai framework for disaster risk reduction 2015-2030. 2015. https://www.unisdr.org/we/coordinate/sendai-framework. Accessed August 23, 2018.

11. World Health Organization; World Organisation for Animal Health; World Bank Group. WHO-OIE Operational Framework for Good Governance at the Human-Animal Interface: Bridging WHO and OIE Tools for the Assessment of National Capacities. 2014. http://www.oie.int/fileadmin/vademecum/ pdf/WHO-OIE_Operational_Framework_final.pdf. Accessed August 23, 2018.

12. World Health Organization. Joint External Evaluation Tool. International Health Regulations (2005). 2d ed. Geneva: WHO; 2018. https://extranet.who.int/sph/sites/default/files/ document-library/document/9789241550222-eng.pdf. Accessed August 23, 2018.

13. World Organisation for Animal Health. OIE Tool for the Evaluation of Performance of Veterinary Services (OIE PVS Tool). Paris, France: OIE; 2013. http://www.oie.int/ fileadmin/Home/eng/Support_to_OIE_Members/pdf/A_PVS_ Tool_Final_Edition_2013.pdf. Accessed August 23, 2018.

14. World Organisation for Animal Health. OIE Tool for the Evaluation of Performance of Veterinary Services andlor Aquatic Animal Health Services (OIE PVS Tool: Aquatic). Paris, France: OIE; 2013. http://www.oie.int/fileadmin/Home/eng/Support_ to_OIE_Members/pdf/A_PVS_Tool_aquatic_animals.pdf. Accessed August 23, 2018.

15. World Health Organization. National Action Plan for Health Security (NAPHS). 2018. https:/extranet.who.int/ sph/country-planning. Accessed August 23, 2018.

16. Rist CL, Arriola CS, Rubin C. Prioritizing zoonoses: a proposed One Health tool for collaborative decision-making. PLoS One 2014;9(10):e109986.

17. US Centers for Disease Control and Prevention. Zoonotic disease prioritization. CDC website. Updated June 21, 2018. https://www.cdc.gov/onehealth/global-activities/prioritization .html. Accessed August 23, 2018.

18. World Organisation for Animal Health. PVS gap analysis. 2018. http://www.oie.int/solidarity/pvs-gap-analysis/. Accessed August 23, 2018.

19. Convention on Biological Diversity. National Biodiversity Strategies and Action Plans (NBSAPs). https://www.cbd.int/ nbsap/. Accessed August 23, 2018.

20. United Nations Framework Convention on Climate Change. National Adaptation Plans. 2018. https:/unfccc.int/topics/ adaptation-and-resilience/workstreams/national-adaptation-planentry-page. Accessed August 23, 2018.

21. PreventionWeb. Policies, plans \& statements: UNISDR. 2018. https://www.preventionweb.net/english/professional/ policies/. Accessed August 23, 2018.

22. University of Minnesota. One Health disease outbreak response tool. 2018. http://license.umn.edu/technologies/ 20170369_one-health-disease-outbreak-response-tool. Accessed August 23, 2018.

23. USAID. Preparedness \& Response. One Health self-assessment tool guide. February 2018. http://preparednessand response.org/news/one-health-self-assessment-tool-guide/. Accessed August 23, 2018. 
24. Mghamba JM, Talisuna AO, Suryantoro L, et al. Developing a multisectoral National Action Plan for Health Security (NAPHS) to implement the International Health Regulations (IHR 2005) in Tanzania. BMJ Glob Health 2018;3(2): e000600.

25. World Health Organization. Tanzania commits to embrace the One Health approach [press release]. February 13, 2018. https://www.afro.who.int/news/tanzania-commits-embraceone-health-approach. Accessed August 23, 2018.

26. Prince Mahidol Award Conference. Bangkok Statement: a call to action on making the world safe from the threats of emerging infectious diseases. 2018. http://pmac2018.com/ site/what_news/detail/5. Accessed August 23, 2018.

27. World Health Organization. Implementation of the International Health Regulations (2005): Report of the Review Committee on Second Extensions for Establishing National Public Health Capacities and on IHR Implementation. Report by the Director-General. January 16, 2015. http://www.who. int/ihr/B136_22Add1-en_IHR_RC_Second_extensions.pdf. Accessed August 23, 2018.

28. Fan VY, Jamison DT, Summers LH. Pandemic risk: how large are the expected losses? Bull World Health Organ 2018; 96(2):129-134.

29. Karesh WB, Dobson A, Lloyd-Smith JO, et al. Ecology of zoonoses: natural and unnatural histories. Lancet 2012; 380(9857):1936-1945.

30. Richardson J, Lockhart C, Pongolini S, et al. Drivers for emerging issues in animal and plant health. EFSA Journal 2016;14(Suppl 1):e00512.

31. USAID. Towards a Safer World. Beyond Pandemics: A Wholeof-Society Appproach to Disaster Preparedness. September 2011. https://reliefweb.int/sites/reliefweb.int/files/resources/ Full_Report_2400.pdf. Accessed August 23, 2018.

32. Jones KE, Patel NG, Levy MA, et al. Global trends in emerging infectious diseases. Nature 2008;451(7181):990993.

33. World Bank. People, Pathogens and Our Planet: The Economics of One Health. Washington, DC: World Bank; 2012. http://documents.worldbank.org/curated/en/612341468147 856529/pdf/691450ESW0whit0D0ESW120PPPvol120web. pdf. Accessed August 23, 2018.
34. World Bank. One Health: Operational Framework for Strengthening Human, Animal, and Environmental Public Health Systems at their Interface. Washington, DC: World Bank; 2018. http://documents.worldbank.org/curated/en/ 703711517234402168/pdf/123023-REVISED-PUBLICWorld-Bank-One-Health-Framework-2018.pdf. Accessed August 23, 2018.

35. Bouley T, Ebi KL, Midgley A, et al. Methodological Guidance: Climate Change and Health Diagnostic: A Country-Based Approach for Assessing Risks and Investing in Climate-Smart Health Systems. Washington, DC: World Bank Group; 2017.

36. World Bank. Geographic Hotspots for World Bank Action on Climate Change and Health. Washington, DC: World Bank Group; 2017.

37. Pan American Health Organization; World Health Organization. Inter American Ministerial Meeting on Health and Agriculture: "One Health and the Sustainable Development Goals." 21-22 July 2016; Asuncion, Paraguay. http://www. panaftosa.org/rimsa17/dmdocuments/RIMSA17-Tendencia Futura_SPV_english_[010716].pdf. Accessed August 23, 2018.

38. World Health Organization; Convention on Biological Diversity. Connecting Global Priorities: Biodivesity and Human Health. A State of Knowledge Review. 2015. https://www.cbd. int/health/SOK-biodiversity-en.pdf. Accessed August 23, 2018.

39. Hasler B, Cornelsen L, Bennani H, Rushton J. A review of the metrics for One Health benefits. Rev Sci Tech 2014; 33(2):453-464.

40. Machalaba C, Smith KM, Awada L, et al. One Health Economics to confront disease threats. Trans R Soc Trop Med Hyg 2017;111(6):235-237.

Address correspondence to: Catherine Machalaba, MPH

Policy Advisor

EcoHealth Alliance

460 West 34th Street - 17th floor New York, NY 10001

Email: machalaba@ecohealthalliance.org 